\title{
Evaluation of glycophenotype in breast cancer by quantum dot-lectin histochemistry
}

This article was published in the following Dove Press journal:

International Journal of Nanomedicine

29 November 2013

Number of times this article has been viewed

\section{Camila G Andrade' \\ Paulo E Cabral Filho \\ Denise PL Tenório ${ }^{3}$ \\ Beate S Santos ${ }^{4}$ \\ Eduardo IC Beltrão' \\ Adriana Fontes ${ }^{2}$ \\ Luiz B Carvalho Jr'}

'Keizo Asami Immunopathology Laboratory, ${ }^{2}$ Biophysics and

Radiobiology Department,

${ }^{3}$ Fundamental Chemistry Department,

${ }^{4}$ Pharmaceutical Science Department,

Federal University of Pernambuco,

Recife, Pernambuco, Brazil
Correspondence: Adriana Fontes Av Prof Moraes Rego, S/N, Departamento de Biofísica e Radiobiologia, CCB, UFPE, 50670-90I, Recife, Pernambuco, Brazil Tel +558121267819

$\mathrm{Fax}+558121268560$

Email adriana.fontes@pesquisador.cnpq.br

\begin{abstract}
Cell surface glycoconjugates play an important role in differentiation/dedifferentiation processes and lectins are employed to evaluate them by several methodologies. Fluorescent probes are considered a valuable tool because of their ability to provide a particular view, and are more detailed and sensitive in terms of cell structure and molecular content. The aim of this study was to evaluate and compare the expression and distribution of glycoconjugates in normal human breast tissue, and benign (fibroadenoma), and malignantly transformed (invasive ductal carcinoma) breast tissues. For this, we used mercaptosuccinic acid-coated Cadmium Telluride (CdTe) quantum dots (QDs) conjugated with concanavalin A (Con A) or Ulex europaeus agglutinin I (UEA I) lectins to detect $\alpha$-D-glucose/mannose and L-fucose residues, respectively. The QD-lectin conjugates were evaluated by hemagglutination activity tests and carbohydrate inhibition assays, and were found to remain functional, keeping their fluorescent properties and carbohydrate recognition ability. Fluorescence images showed that different regions of breast tissue expressed particular types of carbohydrates. While the stroma was preferentially and intensely stained by QD-Con A, ductal cells were preferentially labeled by QD-UEA I. These results indicate that QD-lectin conjugates can be used as molecular probes and can help to elucidate the glycoconjugate profile in biological processes.
\end{abstract}

Keywords: nanoparticles, concanavalin A, Ulex europaeus, carbohydrates, mammary tissues

\section{Introduction}

Despite advances in diagnosis and treatment, breast cancer remains a significant issue in women's health. It is the most frequently diagnosed type of cancer, and although death rates have dropped in recent years, breast cancer is still one of the leading causes of death in women. ${ }^{1,2}$ The recognition of glycans as mediators of important biological processes has stimulated the interest in research related to glycobiology. Glycoconjugates present on the cell surface and in the extracellular matrix play fundamental roles in a variety of biological processes, such as cell-cell interaction, bacterial adhesion, membrane organization, cell immunogenicity, and protein targeting. ${ }^{2}$ Glycan structures depend on cell type, developmental stage, and cell differentiation, and are modified in many pathologic states, including cancers. ${ }^{3}$ Modification of the cell surface and extracellular matrix carbohydrate structures may affect adhesion properties and cell-cell signaling as well as modulate the immune system response. ${ }^{4}$ Disease-associated glycosylation has great potential as a source of tumor-associated markers and in the prediction of tumor behavior. ${ }^{5}$ Identifying changes in glycosylation at an early stage of tumor development may offer the possibility to understand their role in development of disease, monitoring disease progression, and providing tools to guide therapy. ${ }^{6}$ Alterations in cell surface 
glycoconjugates have been reported in a variety of neoplastic lesions. ${ }^{7}$ Lectins are a group of specific glycoproteins that specifically bind to terminal glycans on the cell surface and extracellular matrix glycoconjugates. This ability to bind selectively to carbohydrates makes the lectins a useful tool for studying neoplastic tissues. ${ }^{8,9}$

Conjugates formed between lectins and fluorescent labels have been shown to be promising for investigation of changes in expression of glycoproteins. ${ }^{10}$ Among the fluorescent labels, quantum dots (QDs) are emerging as a new tool for molecular probes. QDs are light-emitting nanoparticles with unique optical properties that overcome traditional organic dyes and fluorescent proteins. Among their advantages, QDs have size-tunable light emission, chemically active surfaces, narrow emission bands, and exceptional resistance to photobleaching. These properties are promising for improving molecular histopathology and diagnosis of disease. ${ }^{11-13}$

Some of us have previously demonstrated the potential of using QD-lectin bioconjugates to diagnose abnormal breast tissues applying $\mathrm{CdS} / \mathrm{Cd}(\mathrm{OH})_{2}$ core shell QDs conjugated to concanavalin A (Con A) to label mammary fibroadenoma tissue. ${ }^{14}$ Confocal image analysis demonstrated that the stained fibroadenoma tissues showed a labeling pattern indicating internal structures in good agreement with the usual peroxidase procedure used to reveal carbohydrate residues. The preliminary findings reported by Santos et al supported the use of Cadmium Sulfide passivate with Cadmium Hydroxide $\left(\mathrm{CdS} / \mathrm{Cd}(\mathrm{OH})_{2}\right)$ QDs as specific probes for cellular alterations, enabling their use in diagnostics. ${ }^{14}$ However, CdTe QDs and their conjugates have more photostable and higher luminescence intensity than $\mathrm{CdS} / \mathrm{Cd}(\mathrm{OH})_{2}$ QDs.

In this context, the aim of this work was to use Cadmium Telluride CdTe QDs conjugated with Con A and Ulex europaeus agglutinin I(UEA I) lectins to investigate carbohydrate distribution and expression on the cell surface and in the extracellular matrix of normal breast tissue and fibroadenoma (benign) and invasive ductal carcinoma (malignant) breast tissues. Using Con A and UEA I, it was possible to compare the distribution of different carbohydrates throughout the tissues because Con A binds $\alpha$-D-glucose and mannose, while UEA I recognizes L-fucose.

\section{Materials and methods}

\section{Materials}

Mercaptosuccinic acid (MSA), cadmium perchlorate $\left(\mathrm{Cd}\left(\mathrm{ClO}_{4}\right)_{2}\right)$, sodium borohydride $\left(\mathrm{NaBH}_{4}\right)$, tellurium $\left(\mathrm{Te}^{0}\right)$, Con A, and UEA I were purchased from Sigma-Aldrich (St Louis, MO, USA) and used without further purification.
Isopropyl alcohol and other routine chemicals were purchased from Vetec (Duque de Caxias, Rio de Janeiro, Brazil). All the chemicals used were of analytical grade and ultrapure water $(18.2 \mathrm{~m} \Omega)$ was used in all experiments.

\section{Synthesis and characterization of MSA-CdTe QDs}

Water-dispersed MSA-CdTe QDs were synthesized according to a previously reported method with some modifications. ${ }^{15}$ Briefly, the QDs were obtained by rapid addition of a solution containing $\mathrm{Te}^{2-}$ ions in a $\mathrm{Cd}\left(\mathrm{ClO}_{4}\right)_{2}$ solution at $0.01 \mathrm{~mol} / \mathrm{L}$, under alkaline conditions. MSA was used as the stabilizing and functionalizing agent. The aqueous $\mathrm{Te}^{2-}$ solution was prepared by reducing metallic tellurium with $\mathrm{NaBH}_{4}$ in a molar ratio of 1:30 $\left(\mathrm{Te}^{0}: \mathrm{NaBH}_{4}\right)$ under a nitrogen-saturated atmosphere. The molar ratio of synthesis was $2: 1: 2.4$ of $\mathrm{Cd}$ to Te to MSA, respectively. After synthesis, the QDs were structurally characterized by X-ray diffraction. The X-ray diffraction analysis was carried out using a Nixdorf D5000 diffractometer (Siemens Corporation, Washington, DC, USA) with $\mathrm{CuK} \alpha$ radiation $(\lambda=0.15418 \mathrm{~nm})$. The X-ray diffraction pattern was performed using MSA-CdTe QDs powder obtained by inducing precipitation of the aqueous QD solution with isopropyl alcohol. Optical characterization of the QDs was carried out by acquiring ultraviolet-visible absorption spectra with an Evolution 600 spectrophotometer (Thermo Scientific, Waltham, MA, USA) and emission and excitation spectra using an LS 55 spectrometer (PerkinElmer, Waltham, MA, USA).

\section{Conjugation of MSA-CdTe QDs to Con A or UEA I}

The MSA-CdTe QDs were conjugated to Con A by an adsorption process. The $\mathrm{pH}$ of the QD suspension was decreased to 8.0 using MSA solution (at $6.8 \mathrm{mg} / \mathrm{mL}$ ). Next, $10 \mu \mathrm{L}$ of Con A (at $28 \mathrm{mg} / \mathrm{mL}$ ) was added to $1 \mathrm{~mL}$ of the QD suspension (containing approximately $10^{15}$ nanoparticles $/ \mathrm{mL}$ ) and the system was gently stirred for 2 hours at $25^{\circ} \mathrm{C}$. Our preliminary experiments showed positive results with the QDs at the original synthesis concentration, so all tests were performed with this concentration.

The nanoparticles were covalently linked to UEA I. For this, the $\mathrm{pH}$ of the nanoparticle suspension was adjusted to 5.5 with MSA $(4.9 \% \mathrm{w} / \mathrm{v})$, and carbodiimide chemistry was applied using 1-ethyl-3[3-dimethylaminopropyl] carbodiimide hydrochloride (EDC) at $0.4 \mathrm{mg} / \mathrm{mL}$ as a zero-length cross-linker. Further, we added N-hydroxysulfosuccinimide $1.1 \mathrm{mg} / \mathrm{mL}$ to the system after 
5 minutes to increase the yield of conjugation. The volume proportion of QDs to EDC to N-hydroxysulfosuccinimide was 1:0.5:0.5 (v:v:v). Finally, $10 \mu \mathrm{L}$ of UEA I (at $28 \mathrm{mg} / \mathrm{mL}$ ) was incubated with $2 \mathrm{~mL}$ of QD-EDC-N-hydroxysulfosuccinimide for 24 hours at $4^{\circ} \mathrm{C}$. The final concentrations of the Con $\mathrm{A}$ and UEA I lectins was $280 \mu \mathrm{g} / \mathrm{mL}$ and $140 \mu \mathrm{g} / \mathrm{mL}$, respectively.

\section{Lectin histochemistry}

Transformed tissues, diagnosed as fibroadenoma (benign) or invasive ductal carcinoma (malignant), and normal mammary tissues were obtained from the Tissue Bank of the Sector of Pathology, Keizo Asami Immunopathology Laboratory, Federal University of Pernambuco, Brazil. Normal mammary tissues were collected from reduction mastoplasty in a plastic surgery clinic. Tissue sections (4 $\mu \mathrm{m})$ were deparaffinized with xylene and hydrated in graded alcohols (100\% to $70 \%)$. Tissue slices were treated with $125 \mu \mathrm{L}$ of a trypsin solution $(0.1 \% \mathrm{w} / \mathrm{v})$ for 2 minutes at $37^{\circ} \mathrm{C}$ and then incubated with $100 \mu \mathrm{L}$ of the QD-Con A or QD-UEA I conjugates for 2 hours at $4^{\circ} \mathrm{C}$, followed by three 5 -minute washings with $5 \mathrm{~mL}$ of $10 \mathrm{mM}$ phosphate buffer according to the method described by Beltrao et al. ${ }^{16}$ Tissues were also incubated with nonconjugated QDs as a control to evaluate labeling.

\section{Characterization of bioconjugates}

The carbohydrate recognition activity of the QD-Con A and QD-UEA I conjugates was evaluated by hemagglutination tests using glutaraldehyde-treated rabbit erythrocytes according to the method reported by Beltrao et al. ${ }^{16}$ To confirm that labeling results were due to lectin carbohydrate specificity, lectin binding inhibition assays were performed by incubating each conjugate with $0.3 \mathrm{M}$ methyl- $\alpha$-D-mannopyranoside (QD-Con A) or L-fucose (QD-UEA I) for 1 hour at $25^{\circ} \mathrm{C}$ prior to incubation with tissues. The following steps for the binding protocol were performed as described previously. We also evaluated the optical properties (absorption, emission, and excitation spectra) of the conjugates to determine if the conjugation process could change the optical characteristics originally shown by the QDs.

\section{Image processing}

Tissue staining was evaluated using a DMI 4000 B fluorescence microscope (Leica Microsystems, Wetzlar, Germany; $40 \times$ objective). A band-pass filter (340-380 nm) was used to excite the fluorescence that was collected by a long-pass filter ( $\geq 425 \mathrm{~nm})$. All images were acquired with a color Pixelfly camera (PCO-TECH Inc., Romulus, MI, USA) applying the same acquisition parameters for all the images acquired.

\section{Results and discussion Characterization of MSA-CdTe QDs}

Structural and optical characterization was used to evaluate the size, fluorescence, and crystallinity of the QDs. The X-ray diffraction pattern for the CdTe QDs showed three diffraction peaks, observed at $2 \theta$ values of $24.2^{\circ}, 40.02^{\circ}$, and $46.42^{\circ}$, respectively, corresponding to the (111), (220), and (311) crystalline planes, as shown in Figure 1A. This result is consistent with a bulk cubic (zinc blend) CdTe structure (Joint Committee on Powder Diffraction Standards - JCPDS No 75-2086). ${ }^{17}$ Applying Scherrer's equation in the first peak of the X-ray diffraction pattern, a diameter of $3.0 \mathrm{~nm}$ was estimated for the QDs. ${ }^{18}$

Figure 1B shows the optical characterization of the original QD suspension. The optical properties of the conjugates (QD-Con A and QD-UEA I) did not show significant changes when compared with the original suspension (data not shown), demonstrating that the conjugation process did not change the optical characteristics originally shown by the QDs. Both the original QD suspension and the QD conjugates showed an emission maximum at $644 \mathrm{~nm}$, with a full width at half maximum of $50 \mathrm{~nm}$. According to the first absorption peak at $586 \mathrm{~nm}$, a diameter of $3.5 \mathrm{~nm}$ for the QDs was estimated, which is in agreement with the X-ray diffraction analysis. ${ }^{19,20}$ MSA-CdTe QDs with diameters around $3.5 \mathrm{~nm}$ and showing red-orange fluorescence were chosen to provide better contrast with the autofluorescence, which was in the blue region under ultraviolet excitation. Further, the original suspension had a concentration of $10^{15}$ particles $/ \mathrm{mL}$, evaluated approximately using the empiric equation devised by Yu et al. ${ }^{21}$

\section{Hemagglutination activity}

Lectin activity was analyzed by the hemagglutination technique before and after conjugation of the MSA-CdTe QDs. The CdTe QDs alone did not show hemagglutination activity, whereas the QD-Con A conjugates displayed activity equal to that of nonconjugated Con A lectin. The same behavior was observed for QD-UEA I, as shown in Table 1. This suggests that the Con A and UEA I carbohydrate recognition sites were preserved after conjugation with MSA-CdTe QDs.

\section{Lectin histochemistry of breast tissues}

Elucidation of the structure and function of cell surface glycoconjugates is relevant for understanding many biological 
A

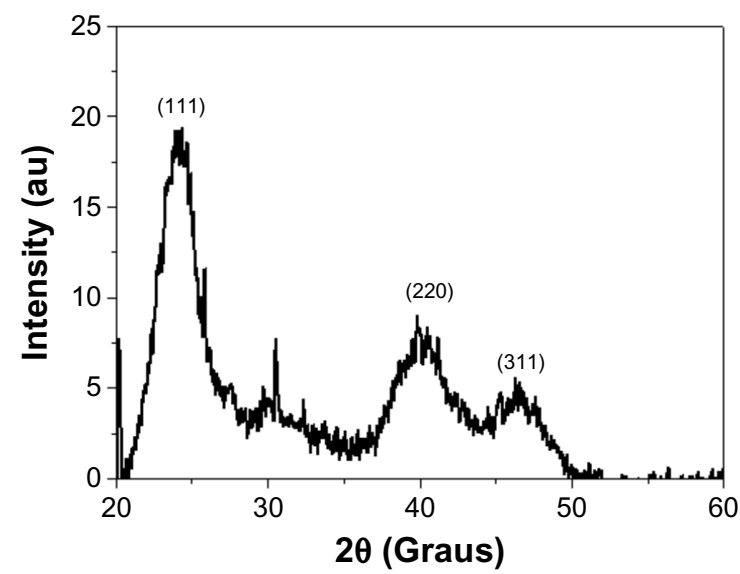

B

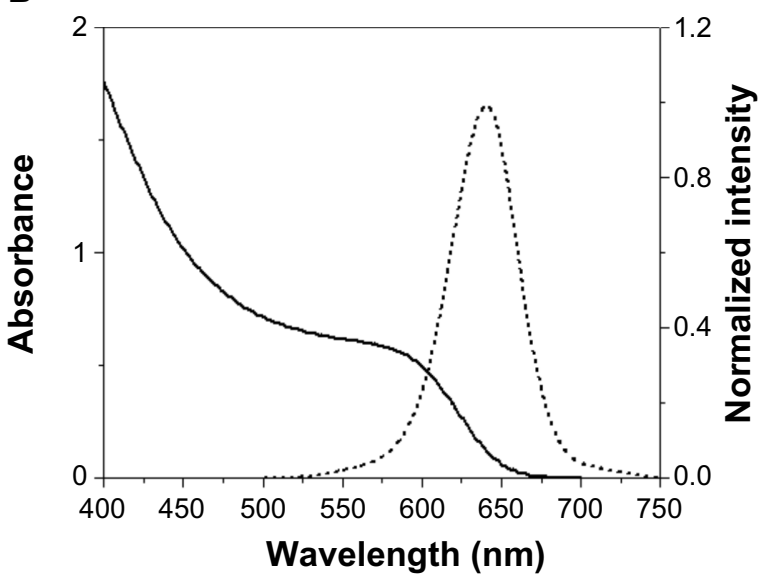

Figure I Structural and optical characterization of mercaptosuccinic acid-coated CdTe quantum dots. (A) X-ray diffraction pattern and (B) absorption (dark line) and emission (dashed line) spectra. The emission spectrum was acquired at $\lambda=365 \mathrm{~nm}$. Abbreviations: au, arbitrary unit; CdTe, Cadmium Telluride.

processes, given that these molecules can affect cellular differentiation, adhesion, and the immune response. ${ }^{22}$ Experimental evidence has shown that tumor development is associated with a variety of altered cell glycosylation patterns. ${ }^{23}$

QD-Con A and QD-UEA I conjugates were used separately to investigate the expression profiles of $\alpha$-D-glucose/ mannose and L-fucose in normal breast tissue, benign transformed breast tissue (fibroadenoma), and malignant transformed breast tissue (invasive ductal carcinoma), as shown in Figure 2. No staining of mammary tissues was observed when nonconjugated QDs were used (data not shown).

Figure 3 shows hematoxylin and eosin images of normal, fibroadenoma, and invasive ductal carcinoma tissues, providing better identification of tissue compartments (cells indicated by yellow arrows and stroma indicated by asterisks) in the fluorescence analyses.

Autofluorescence emitted by a tissue specimen can be visualized in the blue-green region while fluorescence emitted by QDs is visualized in the red-orange region. As shown in Figure 2, the QD-Con A conjugates were able to bind intensively and preferentially to stroma in the normal

Table I Hemagglutination activity of Con A and UEA I, MSACdTe QDs, and QD-Con A and QD-UEA I conjugates

\begin{tabular}{ll}
\hline Systems & Titer (HU) \\
\hline MSA-CdTe QDs & No activity \\
Con A & 64 \\
QD-Con A & 64 \\
UEA I & 32 \\
QD-UEA I & 32 \\
\hline
\end{tabular}

Abbreviations: $\mathrm{HU}$, hemagglutination units; CdTe, Cadmium Telluride; QDs, quantum dots; MSA, mercaptosuccinic acid; Con A, concanavalin A; UEAI, Ulex europaeus agglutinin $\mathrm{I}$. breast, fibroadenoma, and invasive ductal carcinoma samples. Despite the preference for stroma, the QD-Con A conjugate also stained ductal cells heterogeneously in some samples (especially those for fibroadenoma).

On the other hand, QD-UEA I conjugates were also seen to bind preferentially to normal and invasive ductal carcinoma cells (Figure 2), since they showed greater fluorescent
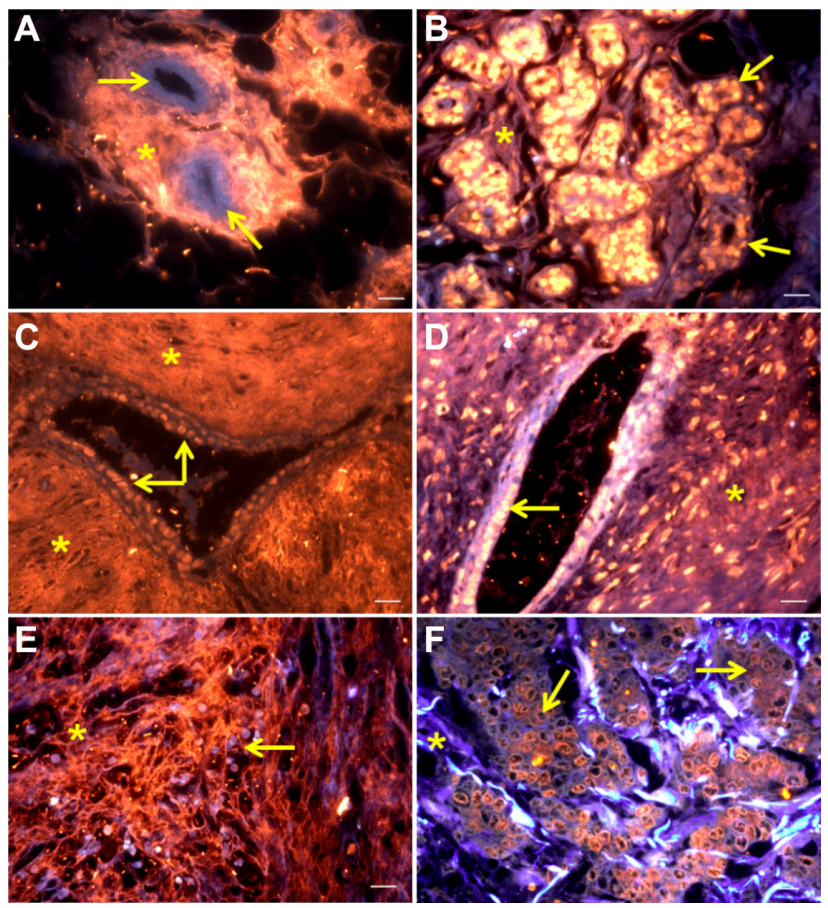

Figure 2 Mammary tissues stained by QD-Con A: normal breast (A), fibroadenoma (C), and invasive ductal carcinoma (E). Mammary tissues labeled with QD-UEA I: normal breast (B), fibroadenoma (D), and invasive ductal carcinoma (F). Notes: Scale bar $20 \mu \mathrm{m}$. Tissue autofluorescence is shown in blue. QD-Con A and QD-UEA I labeling is shown in red-orange. Yellow arrows indicate ductal cells whereas asterisks indicate stromal areas. Excitation by ultraviolet light.

Abbreviations: QD-Con A, quantum dot-concanavalin A conjugate; QD-UEA I, quantum dot-Ulex europaeus agglutinin I conjugate. 


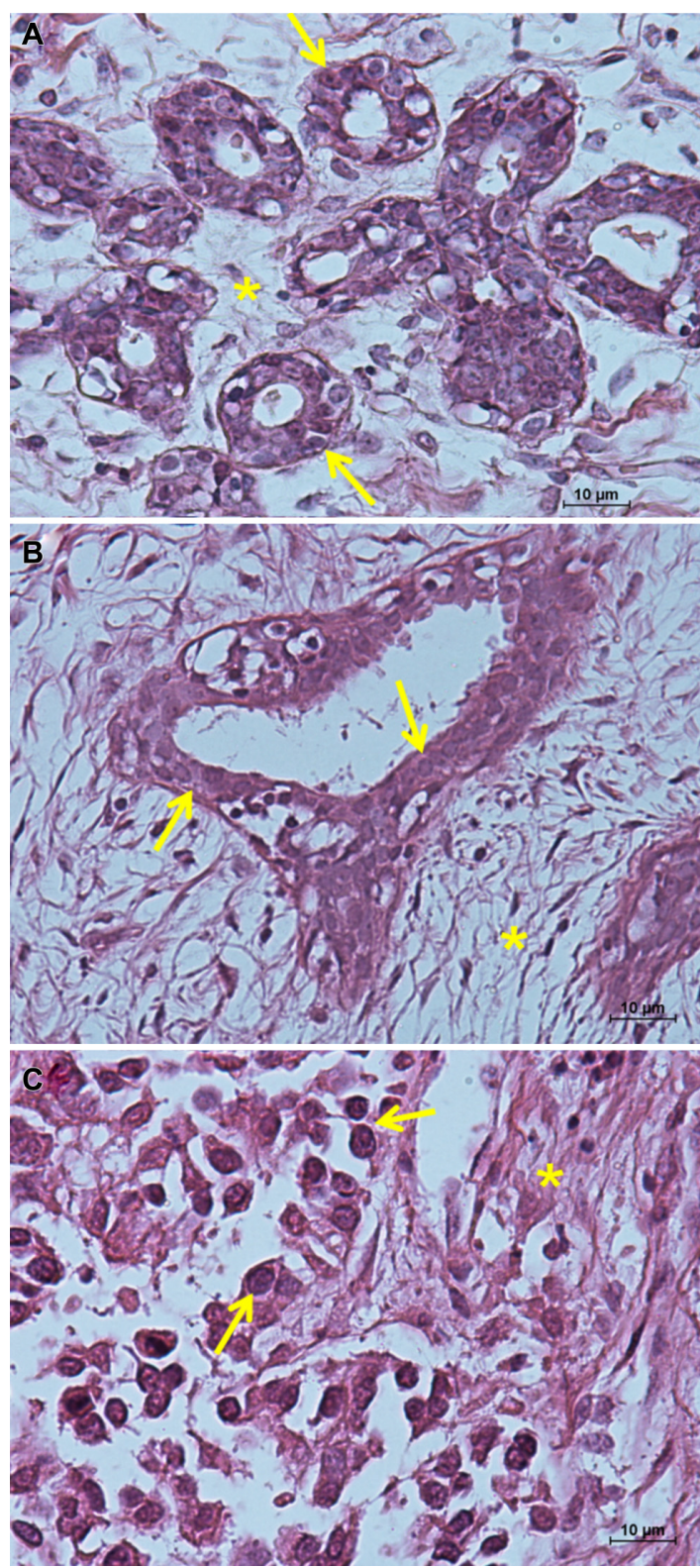

Figure 3 Hematoxylin and eosin images. (A) Normal mammary tissue, (B) fibroadenoma tissue, and (C) invasive ductal carcinoma tissue. Yellow arrows indicate ductal cells while the stroma is indicated by asterisks. Scale bar $10 \mu \mathrm{m}$.

labeling when compared with other tissue structures (especially in normal and invasive ductal carcinoma breast tissues). Fibroadenoma, in particular, showed weak labeling of the stroma by the QD-UEA I conjugate, but even in this case, the cells still showed higher fluorescence. Although adsorption is not a strong interaction due to lack of chemical bonds, the results obtained with the QD-Con A conjugate were successfully reproduced.

These results indicate that distribution of $\alpha$-D-glucose/ mannose and L-fucose among the tissues was directly related to glycosyltransferases and glycosidase activity. Interestingly, staining by the QD-UEA I conjugate revealed a distinct pattern of distribution and expression of carbohydrates throughout the tissues when compared with staining by the QD-Con A conjugate. The images showed a high distribution of $\alpha$-D-glucose/mannose residues in stromal areas in all tissues. In fibroadenoma, it was found that these glycans are present in high concentrations not only in the stroma but also in some ductal cells, as was also reported by Beltrao et al. ${ }^{16}$ Abundant L-fucose residues were found in ductal cells, including in malignant ones. This glycan has been proposed as a potentially critical molecule in neoplasia, including that of the breast. Clinical studies have provided evidence that overexpression of fucosylated cell surface molecules is correlated with metastasis and a poor prognosis. ${ }^{24}$

Most of the studies performed on breast cancer focus on epithelial cells, and not so much attention is given to the surrounding stroma. However, together with extracellular matrix components, stroma cells such as fibroblasts provide the microenvironment that is essential for cancer progression. In this way, stromal alterations can accompany or even precede the malignant transformation of epithelial cells. ${ }^{25}$ The extracellular matrix is a complex bioenvironment composed of glycoproteins, collagen, glycosaminoglycans, and proteoglycans. Thus, lectins are able to interact with carbohydrate residues present in the extracellular matrix. Type I collagen, found in the extracellular matrix, has been recognized as important for the initiation and progression of breast cancer. ${ }^{26}$ Therefore, the QD-Con A conjugate, which stained the stroma intensely, could be a helpful tool in the search for new cancer biomarkers provided by the stroma.

CdTe QDs have been previously conjugated to UEA I as a probe to obtain images of human umbilical vein endothelial cells. ${ }^{27}$ This lectin conjugated to horseradish peroxidase has also been used to study carbohydrate expression in tumor cells. ${ }^{28}$ To our knowledge, this is the first description of glycans distribution in mammary tumors using QD-UEA I as probes.

We did not observe any obvious difference in labeling by QD-Con A in the tissues evaluated in this study. Beltrao et al, using Con A and Cratylia mollis lectin conjugated to peroxidase, noticed that invasive ductal carcinoma tissues showed a higher intensity of staining than fibroadenoma tissues. ${ }^{16}$ On the other hand, Brustein et al, using Con A and peanut agglutinin lectins conjugated to acridinium ester, found that chemiluminescence was higher in fibroadenoma than in invasive ductal carcinoma for both lectins tested. ${ }^{29}$ This shows that, in addition to the method of labeling or detection used, pretreatment of tissues, such as formalin-fixing and paraffin-embedding, plays an important role in the intensity 


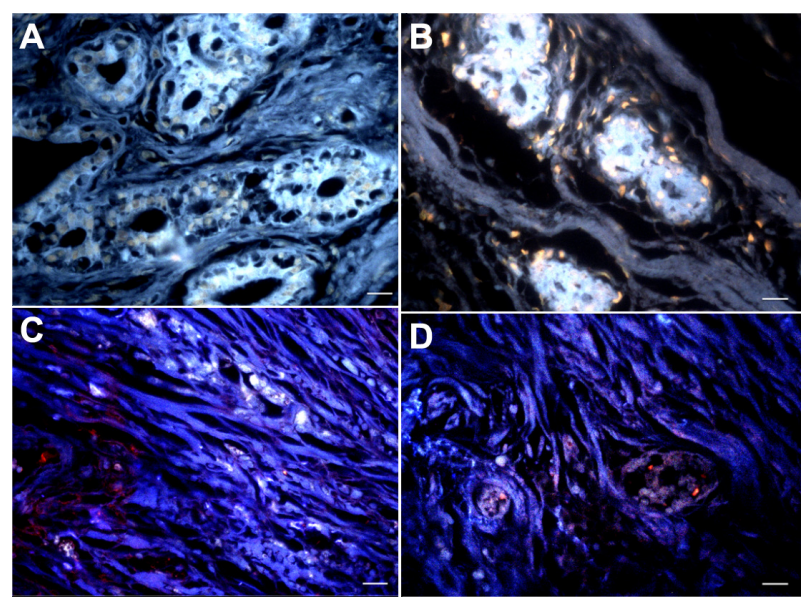

Figure 4 Carbohydrate-lectin inhibition assays. (A and B) Fibroadenoma samples incubated with inhibited QD-Con A and QD-UEA I conjugates, respectively. (C and D) Invasive ductal carcinoma samples incubated with inhibited QD-Con A and QD-UEA I, respectively. Scale bar $20 \mu \mathrm{m}$.

Abbreviations: QD-Con A, quantum dot-concanavalin A conjugate; QD-UEA I, quantum dot-Ulex europaeus agglutinin I conjugate.

of staining evaluation. More studies are underway to give us a better understanding of labeling intensity.

\section{Carbohydrate-lectin inhibition assay}

The inhibition assay was performed using methyl- $\alpha-D-$ mannopyranoside and L-fucose sugars for QD-Con A and QD-UEA I, respectively (Figure 4). After incubation with these specific carbohydrates, there was a dramatic decrease in the labeling pattern, both in fibroadenoma and invasive ductal carcinoma. Because the lectin carbohydrate-recognition sites are occupied, no interaction occurred between the QD conjugates and cell surface glycoconjugates of stromal and ductal cells. This result indicates that binding between QD-Con A and QD-UEA I conjugates and cell surface carbohydrates is specific. Further, these results, along with those for the hemagglutination assays (see Table 1), show that lectins are capable of recognizing carbohydrates, even after the conjugation process, which was demonstrated to be effective.

\section{Conclusion}

Analysis of the conjugates showed that the conjugation process did not change the optical properties of the QDs or affect the capacity of lectins conjugated to QDs to recognize carbohydrates. CdTe QDs are emerging as promising labeling tools, given that they are highly photostable and show intense fluorescence, and have a flexible spectral range (from green to near infrared) tunable with their size. The QD-Con A and QDUEA I conjugates showed distinct staining patterns, revealing differences in $\alpha$-D-glucose/mannose and L-fucose residue expression and distribution in fibroadenoma, invasive ductal carcinoma, and normal breast tissues. As shown by inhibition assays, interaction between the conjugates and stromal and cell surface molecules is very specific. These results indicate the potential of QD-lectin conjugates as molecular probes capable of providing new information about cellular and extracellular matrix structures, molecular content, and tumor environment, which may help to elucidate biological processes including the development and progression of cancer.

\section{Acknowledgments}

This paper was supported by the Coordination for the Improvement of Higher Education Personnel (CAPES), the National Council for Scientific and Technological Development (CNPq), and the Foundation for Science and Technology of Pernambuco (FACEPE). This work is also linked to the National Institute of Photonics.

\section{Disclosure}

The authors report no conflicts of interest in this work.

\section{References}

1. Jemal A, Siegel R, Xu J, Ward E. Cancer statistics, 2010. CA Cancer J Clin. 2010;60:277-300.

2. Adamczyk B, Tharmalingam T, Rudd PM. Glycans as cancer biomarkers. Biochim Biophys Acta. 2012;1820:1347-1353.

3. Cazet A, Julien S, Bobowski M, Burchell J, Delannoy P. Tumourassociated carbohydrate antigens in breast cancer. Breast Cancer Res. 2010;12:204.

4. Potapenko IO, Haakensen VD, Lüders T, et al. Glycan gene expression signatures in normal and malignant breast tissue; possible role in diagnosis and progression. Mol Oncol. 2010;4:98-118.

5. Fry SA, Afrough B, Lomax-Browne HJ, Timms JF, Velentzis LS, Leathem AJ. Lectin microarray profiling of metastatic breast cancer. Glycobiology. 2011;21:1060-1070.

6. Rambaruth ND, Dwek MV. Cell surface glycan-lectin interactions in tumor metastasis. Acta Histochem. 2011;113:591-600.

7. Gallegos B, Pérez-Campos E, Martinez R, et al. O-glycosylation expression in fibroadenoma. Prep Biochem Biotechnol. 2010;40:1-12.

8. Arab MR, Sepehri Z, Eimani H, Karimi M, Aval FS. Histochemical study of $\mathrm{N}$-acetylgalactosamine containing glycoconjugate in intraductal carcinoma of the breast by HPA lectin. Yakhteh Med J. 2006; 7(4):216-221.

9. Kumar KK, Chandra KL, Sumanthi J, Reddy GS, Shekar PC, Reddy B. Biological role of lectins: a review. J Orofac Sci. 2012;4:20-25.

10. Zhelev Z, Ohba H, Bakalova R, et al. Fabrication of quantum dotlectin conjugates as novel fluorescent probes for microscopic and flow cytometric identification of leukemia cells from normal lymphocytes. Chem Comm (Camb). 2005;15:1980-1982.

11. Sukhanova A, Venteo L, Devy J, et al. Highly stable fluorescent nanocrystals as a novel class of labels for immunohistochemical analysis of paraffin-embedded tissue sections. Lab Invest. 2002;82: 1259-1261.

12. Gao X, Yang L, Petros JÁ, Marshall FF, Simons JW, Nie S. In-vivo molecular and cellular imaging with quantum dots. Curr Opin Biotechnol. 2005;16:63-72.

13. Yezhelyev MV, Gao X, Xing Y, Al-Hajj A, Nie S, O'Regan RM. Emerging use of nanoparticles in diagnosis and treatment of breast cancer. Lancet Oncol. 2006;7:657-767. 
14. Santos BS, Farias PMA, Menezes FD, et al. CdS-Cd(OH)2 core shell quantum dots functionalized with Concanavalin A lectin for recognition of mammary tumors. Phys Status Solidi C. 2006; 3(11):4017-4022.

15. Santos BS, Farias PMA, Menezes FD, et al. New highly fluorescent biolabels based on II-VI semiconductor hybrid organic-inorganic nanostructures for bioimaging. Appl Surf Sci. 2008; 255(3):790-792.

16. Beltrão EI, Correia MT, Figueredo-Silva J, Coelho LC. Binding evaluation of isoform 1 from Cratylia mollis lectin to human mammary tissues. Appl Biochem Biotechnol. 1998;74:125-134.

17. Lalitha S, Sathyamoorthy R, Senthilarasu S, Subbarayan A. Influence of $\mathrm{CdCl}_{2}$ treatment on structural and optical properties of vacuum evaporated CdTe thin films. Solar Energ Mater Solar Cells. 2006;90: 694-703.

18. Cullity BD. Elements of X-ray Diffraction. 3rd ed. Boston, MA: Addison-Wesley Publishing Company Inc; 1967.

19. Dagtepe P, Chikan V, Jasinski J, Leppert VJ. Quantized growth of CdTe quantum dots: observation of magic-sized CdTe quantum dots. J Phys Chem C. 2007;111:14977-14983.

20. Rogach AL, Franzl T, Klar TA, et al. Aqueous synthesis of thiolcapped CdTe nanocrystals: state-of-the-art. J Phys Chem C. 2007;111: 14628-14637.

21. Yu WW, Qu L, Guo W, Peng X. Experimental determination of the extinction coefficient of CdTe, CdSe, and CdS nanocrystals. Chem Mater. 2003;15:2854-2860.

22. Shimma Y, Jigami Y. Expression of human glycosyltransferase genes in yeast as a tool for enzymatic synthesis of sugar chain. Glycoconj J. 2004;21:75-78.
23. Ghazarian H, Idoni B, Oppenheimer SB. A glycobiology review: carbohydrates, lectins and implications in cancer therapeutics. Acta Histochem. 2011;113:236-247.

24. Listinsky JJ, Siegal GP, Listinsky CM. The emerging importance of $\alpha$-L-fucose in human breast cancer: a review. Am J Transl Res. 2011;3: 292-322.

25. Micke P, Östman A. Tumour-stroma interaction: cancer-associated fibroblasts as novel targets in anti-cancer therapy? Lung Cancer. 2004;45:163-175.

26. Ambekar R, Lau TY, Walsh M, Bhargava R, Toussaint KC Jr. Quantifying collagen structure in biopsies using second-harmonic generation imaging. Biomed Opt Express. 2012;3:2021-2035.

27. Weng J, Song X, Li L, et al. Highly luminescent CdTe quantum dots prepared in aqueous phase as an alternative fluorescent probe for cell imaging. Talanta. 2006;70:397-402.

28. Ito N, Imai S, Haga S, Nagaike C, Morimura Y, Hatake K. Localization of binding sites of Ulex europaeus I, Helix pomatia and Griffonia simplicifolia $\mathrm{I}_{-} \mathrm{B}_{4}$ lectins and analysis of their backbone structures by several glycosidases and poly-N-acetyllactosamine-specific lectins in human breast carcinomas. Histochem Cell Biol. 1996;106:331-339.

29. Brustein VP, Cavalcanti CL, de Melo-Junior MR, Correia MT, Beltrão EI, Carvalho LB Jr. Chemiluminescent detection of carbohydrates in the tumoral breast diseases. Appl Biochem Biotechnol. 2012;166:268-275.
International Journal of Nanomedicine

\section{Publish your work in this journal}

The International Journal of Nanomedicine is an international, peerreviewed journal focusing on the application of nanotechnology in diagnostics, therapeutics, and drug delivery systems throughout the biomedical field. This journal is indexed on PubMed Central,

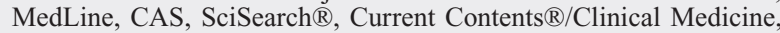

\section{Dovepress}

Journal Citation Reports/Science Edition, EMBase, Scopus and the Elsevier Bibliographic databases. The manuscript management system is completely online and includes a very quick and fair peer-review system, which is all easy to use. Visit http://www.dovepress.com/ testimonials.php to read real quotes from published authors. 